\title{
Strategy Discussion on Improving Knowledge Level of Science Education of Student Teacher Majoring in Preschool Education
}

\author{
Xingmao Jiang \\ Linyi University Feixian Campus \\ jxm_1234@126.com
}

Keywords: Preschool education; Science education; Knowledge; Strategy

\begin{abstract}
There are five courses in kindergarten education field at present, including language, art, health, society, and science. Most preschool teachers feel fear of science education, and only a few preschool teachers can organize scientific inquiry activity in kindergarten. This phenomenon shows that science education for preschool teachers and students need to be strengthened. This paper analyzes knowledge meaning and knowledge structure of scientific education, defines science education knowledge, and discusses strategies of improving knowledge level of science education by analyzing influencing factors and current situation of knowledge level of science education.
\end{abstract}

\section{Knowledge Summary of Science Education}

Meaning of Science Education. Science Educational Knowledge is "how to teach Scientific Knowledge", belonged to scope of teachers' knowledge, and is intellectual resource must possessed by teachers engaged in scientific teaching activities. Its richness and performance situation directly determine the level of teachers' teaching level. Especially from some excellent and experienced teachers, we can find: Science Educational Knowledge is a unique intellectual skills which is embodied from science course teachers in teaching activities. Science Educational Knowledge is a kind of knowledge distinguished from scientific experts for science teachers, including knowledge in Science Teaching, scientific subject's knowledge understood by students and promoted by scientific activities designed by teachers, and knowledge acquired by teachers' scientific teaching practice and experience.

Structure of Science Education. Professor Shulman of Stanford University has done a lot of researches on teacher knowledge, which are mainly conducted among the novice teachers.

The researches aim to make clear what roles subject knowledge play in those novice teachers' teaching plans and teaching procedures. He divided teacher knowledge into three parts, subject knowledge, knowledge of Subject Teaching Methodologies and curriculum knowledge. Based on study, Shulman as well as his colleagues and students made some revise on structure and added four types of knowledge. Therefore, what teacher knowledge put forward by Shulman consists of seven types of knowledge, including general pedagogic knowledge, curriculum knowledge, pedagogic content knowledge, knowledge in character of learners and learning, educational situation knowledge, educational ideas, and knowledge of educational values the framework of teacher knowledge put forward by Shulman has far-reaching influence on later research. Based on this framework, many follow-up researchers modify and improve it, but all of them don't break away from it. Synthesizing Grossman's views on teacher knowledge, drawing lessons from Yang Caixia's research on Science Educational Knowledge, this paper sums up Science Educational Knowledge that a professional teacher should possess in following four aspects: knowledge in science curriculum, scientific teaching methods, learning methods for learners, as well as evaluation of scientific learning. Then, correspondingly, Science Educational Knowledge for kindergarten teachers includes knowledge in science curriculum, children development, scientific teaching methods and strategies, and valuation of scientific learning. 


\section{Factors Affecting Level of Science Education Knowledge}

For pre-service kindergarten teachers who will work there, teaching preparation which is made by normal university students majoring in preschool education will determine whether their later teaching activities are successful. It contains knowledge in subject, pedagogy and children's psychological development when in pre-service education or training. Factors affecting level of pedagogical content knowledge for science of normal university students majoring in preschool education are mainly represented in following aspects.

Knowledge of Science Curriculum in Systematization, Integrity and Portability has much Influence on Level of Science Educational Knowledge. Science curriculum knowledge should include all the science courses in the student's learning process, such as physics, chemistry, biology, geography. And the subject knowledge covers all scientific education activities of the kindergarten, which provides sufficient preparation for those later teaching. Meanwhile, it should also embrace the content of textbooks that are used in the scientific education activities. The systematization, integrity and portability of knowledge in the two aspects will affect the level of pedagogical content knowledge for science. Apart from course knowledge, knowledge of science curriculum should also incorporate knowledge concerned with curriculum theory, namely, the design, content, goal and other aspects of curriculum. It is worth noting that knowledge of kindergarten science curriculum theory has a striking impact on level of Science Educational Knowledge.

Course Features from which Children Absorb Knowledge Lay an Influence of Level of Science Educational Knowledge. Since knowledge for children to learn is of wide scope and multiple content, it is impossible for every kindergarten teacher to completely acquire and understand it.

Nevertheless, when it comes to each discipline, children's mentality will have diverse characteristics. As for science, distinct discipline characteristics will emerge when children are learning science knowledge, establishing their understanding of science and participating in the scientific activities. Therefore, in kindergarten science education, we should focus on children's understanding of science when choosing education content, setting education targets as well as designing and organizing scientific activities. For students majoring in preschool education, the extent they acquire knowledge that children need to learn also influences their level of pedagogical content knowledge for science.

Degree of Science Educational Knowledge is also impacted by Abundance and Multiplicity of Methods and Strategy Knowledge of Science Education. The methods and strategy knowledge of science education refers to knowledge concerned with pedagogics, which is to utilize current subject knowledge to organize and carry out kindergarten science education. This kind of knowledge serves as core Science Educational Knowledge. To speak in a detailed way, it ought to embody primary ability for working as a teacher as well as capability to design, organize and carry out scientific activities that are required in kindergarten science education.

\section{Current Situation of Science Educational Knowledge Level of Normal School Students Majoring in Preschool Education}

First of all, normal school students majoring in preschool education generally put an emphasis on disciplines like music, art and dance before their teaching career.

However, science education is left out by students, teachers as well as education managers to different degree. This result in phenomenon that normal school students majoring in preschool education has an inferior command of Science Educational Knowledge. Second, learning method these normal school students adopt before starting their teaching career is mainly focused on subject education. Besides, subject knowledge they acquire is also separated and independent. Though they have learned pedagogics, child psychology and other subjects, yet these curricula have weak integrity and transplantablity. Thus they are unable to be of great help in kindergarten science education when they begin their teaching career. Furthermore, owing to course design and class arrangement, students have no ample time to practice, which will give rise to situation that 
pre-service education severely mismatches in-service teaching. According to a research, level of Science Educational Knowledge of pre-service students is substantially lower than that of in-service kindergarten teachers. However, in terms of science curriculum knowledge, students in pre-service study period have a greater command than in-service kindergarten teachers. But when it comes to methods and strategy knowledge of science education, the latter is absolutely more capable than the former. This manifests importance of practice. In view of this, in pre-service education period, we should vigorously launch a reform on student science education to enhance their Science Educational Knowledge and science cultivation so as to meet demand of kindergarten science education.

\section{Strategy on Improving Knowledge Level of Science Education of Student Teacher Majoring in Preschool Education}

Positioning Centered Teaching Target to Develop Students' Level of Science Educational Knowledge, Vocational Ability. Due to obsolescence of teaching content, backward teaching mode and single teaching goal, students can not apply basic course of natural science. In order to reform teaching of basic course of natural science, we should accurately locate teaching objectives under guiding ideology of "taking students as center, taking ability as basis and cultivating knowledge level of science education". Modern science education is not only to impart scientific knowledge and methods, but also to increase scientific way of thinking, to cultivate scientific spirit and scientific attitude, to improve scientific exploration and innovation ability. Modern science education in education goals, to cultivate people's scientific literacy as center.

Reasonable Organization and Arrangement of Course Content, Set Time, Reflect Professional, Targeted and Teacher. According to development of preschool education institutions and all kinds of kindergartens, according to characteristics of kindergarten, we carefully analyze knowledge, ability and quality requirements of kindergarten teachers' professional work tasks. In terms of organization and arrangement of teaching content, follow basic law of students' professional ability training. To real work tasks and their work process as basis for integration, order of teaching content, learn from others. Some typical cases of kindergarten teaching at home and abroad are selected and advanced teaching modes are added. The content of practice training is added to make content of teaching both theoretically and practically. Timely introducing the latest educational reform teaching and learning results, focusing on students' innovative thinking and independent analysis of problems, problem-solving ability. At the same time, the curriculum closely with the kindergarten first-line needs to design teaching content, and boldly teaching methods reform, creating a series of pre-school professional characteristics of teaching methods. With particular emphasis on close connection with actual needs of kindergarten positions, pay attention to practical skills of students; effectively improve students' practical ability.

Emphasizing on vocational ability training, scientific design of learning tasks, teaching, learning and doing, integration of theory and practice, training, practice and other aspects of teaching design reasonably. Cooperating with kindergartens to develop course based on work process and design, fully reflect occupation, practical and open requirements. Lead students to practical teaching environment in kindergarten for practical ability training, increase training of vocational skills.

Innovate Teaching Methods; Strengthen Practice, Student-Centered Construction Of Practical Teaching System, and Highlight Practice. In teaching mainly to highlight cultivation of students' scientific literacy and science education level of knowledge-based methods. At present, teacher to teach main law, only focus on importance of theoretical knowledge indoctrination, ignoring kindergarten student's science education level and scientific literacy training.

Especially lack of kindergarten teachers in the future how to guide children to carry out scientific activities of training methods. Strengthen kindergarten teacher's pre-vocational education knowledge and training to improve smooth docking to carry out post-kindergarten science education activities. First of all, according to teaching content, teaching objectives, use corresponding teaching method, case teaching method, insinuation teaching method, on-site 
teaching method, discussion method and other teaching methods. Cultivate practical ability on the basis of grasping essential theoretical knowledge.

Integrate information technology tools and curriculum reasonably. Highlight advantages of information technology means. Pay attention to constructing Subject Teaching Resources. Train students' innovative thinking and master solid academic knowledge at the same time. Furthermore, advocate a new type of teaching structure, that is, combination of teacher -directed and student subject. That is, role of teacher-led play in provision of information resources, cooperative learning organization, research study guidance and independent learning strategy design .etc.

And main role of students is creating scene, weaving theme of process of autonomous active network learning to play. Lay a good foundation for sustainable development of student.

Construct Science Class Training Room and Emphasis on Experience of Teaching Process. Modern science education emphasizes students' practice activities about hands and brain to obtain scientific knowledge, scientific attitudes and scientific methods.

Therefore, teaching of basic course of natural science should not pay attention to students' scientific literacy and study of theory of scientific education, but to improve students' ability of scientific education practice. According to available environment and resources, construction of pre-school education professional science training room. The construction of such training room can be set modeling kindergarten district corner, and dividing training room into several regions. Such as human body structure area, planting and breeding area, astronomical geographical area, environmental protection area, science and technology living area .etc. According to characteristics of knowledge areas, various regions can be configured observation and operation of materials, such as objects, pictures, and models. Open up a tool and multimedia area and equip with some common tools and multimedia equipment. This layout and construction of training room can attract students' participation. And according to different needs of students and teaching, create new environment and change materials. On the one hand, develop students' ability of arranging science education environment, and sprouting students' interest and learning motivation. On the other hand, it can simulate situation and science education of kindergarten. A multipurpose room that using teaching resources to maximize, so students' scientific literacy is further improved. Moreover, construct campus science knowledge propaganda column, and updated once a week to form a good campus culture of science and culture. Hold scientific literacy competitions on a regular basis to arouse students' enthusiasm and interest in learning natural science knowledge.

\section{Conclusion}

Preschool science education is increasingly paid attention by by various parties, to ensure effective development of kindergarten science education activities, it is necessary to improve knowledge level of science education of preschool normal students. In kindergarten teachers' pre-service learning phase, we should increase science education and improve students' scientific literacy further. In the learning process, increase students' practical training, and this can lay a good foundation for smoothly developing scientific teaching of kindergarten teachers.

\section{References:}

[1] Fan Lianghuo.Teacher's Teaching Knowledge Development Research [M]. East China Normal University, 2003.

[2] Ding Banging. Introduction to International Science Education [M]. Taiyuan: Shanxi Education Press, 2002.

[3] Department of Teacher Education, Ministry of Education, Teacher Operationalization Theory and Practice [M]. Beijing: People's Education Press, 2003.

[4] Pang Lijuan. Teacher and Child Development [M]. Beijing: Beijing Normal University Press, 2001. 
[5] Liu Qinghua. Model Construction Research on Teacher knowledge [M]. Beijing: Chinese Academy of Social Sciences Press, 2004.

[6] Zhang Jun. Kindergarten science education [M]. Beijing: People's Education Press, 2003.

[7] Liu Zhanlan. Preschool Science Education [M]. Beijing: Beijing Normal University Press, 2000.

[8] Yang Caixia, Yang Caimei. Research on Orientation and Development of teachers' knowledge [J]. Education Magazine, 2006(1).

[9] Yang Caixia. Analysis on Kindergarten Teachers' Characteristics of Science Curriculum Knowledge [J]. Teacher Development and Teacher Education, 2006(9).

[10] Yang Caixia. Knowledge Essence, Characteristics and Structure of Science Teaching [J]. Educational Science, 2006(1). 